\title{
Is the beta3-adrenoceptor (ADRB3) a potential target for uterorelaxant drugs?
}

\author{
Marc Bardou*1, Céline Rouget ${ }^{1,2,3}$, Michèle Breuiller-Fouché3, \\ Catherine Loustalot ${ }^{4}$, Emmanuel Naline ${ }^{3}$, Paul Sagot ${ }^{4}$, René Frydman ${ }^{5}$, \\ Esteban J Morcillo ${ }^{6}$, Charles Advenier ${ }^{3}$, Marie-Josèphe Leroy ${ }^{3}$ and \\ John J Morrison ${ }^{7}$
}

\begin{abstract}
Address: ${ }^{1}$ Laboratoire de Physiologie et Pharmacologie Cardiovasculaires Expérimentales (LPPCE), Faculté de Médecine, Université de Bourgogne, 7 Bd Jeanne d'Arc, BP 87900, 21079 Dijon Cedex, France, 2UPRES EA220 - Pharmacologie, UFR Biomédicale des Saints Pères, Université Paris 5 , 45 rue des Saints Pères, 75006 Paris, France, ${ }^{3}$ Unité INSERM U767, Faculté des Sciences Pharmaceutiques et Biologiques, Université René Descartes, Université Paris 5, 75006 Paris, France, 4Department of Gynaecology and Obstetrics, CHU du Bocage, 21 Bd de Lattre de Tassigny, BP 1542, 21000 Dijon, France, ${ }^{5}$ Department of Gynaecology and Obstetrics, Antoine Béclère Hospital, 157 rue de la Porte de Trivaux, 92141 Clamart Cedex, France, ${ }^{6}$ Department of Pharmacology, University of Valencia, Av. Blasco Ibanez 17, 46010 Valencia, Spain and ${ }^{7}$ Department of Gynaecology and Obstetrics, National University of Ireland Galway, Clinical Science Institute, University College Hospital Galway, Galway, Ireland
\end{abstract}

Email: Marc Bardou* - marc.bardou@u-bourgogne.fr

* Corresponding author

from Special Non-Invasive Advances in Fetal and Neonatal Evaluation Network of Excellence, First and Second European Workshops on Preterm Labour Tarragona, Spain. 2I-22 September 2006 and 22 June 2005

Published: I June 2007

BMC Pregnancy and Childbirth 2007, 7(SuppI I):SI4 doi:I0.II86/I47I-2393-7-SI-SI4

This article is available from: http://www.biomedcentral.com/|47|-2393/7/SI/SI4

C 2007 Bardou et al; licensee BioMed Central Ltd.

This is an open access article distributed under the terms of the Creative Commons Attribution License (http://creativecommons.org/licenses/by/2.0), which permits unrestricted use, distribution, and reproduction in any medium, provided the original work is properly cited.

\begin{abstract}
The management of premature birth still remains unsatisfactory. Since the relative lack of efficiency and/or safety of current tocolytic agents have been highlighted, it is necessary to develop new uterorelaxant drugs deprived of important maternal and foetal side effects. Our work reported in this review focuses on a potential new target for tocolytic drugs, the $\beta_{3}$-adrenoceptor (ADRB3). This third type of ADRB is shown to be present and functional in human myometrium. We demonstrated that ADRB3 agonists are able to inhibit in-vitro spontaneous contractions of myometrial strips, via a cyclic AMP-mediated pathway. Furthermore, we established that ADRB3 is the predominant subtype over the ADRB2 in human myometrium and that its expression is increased in near-term myometrium, compared to non-pregnant myometrium. Finally, we reported that contrary to ADRB2, the human myometrial ADRB3 is resistant to long-term agonist-induced desensitisation. These compelling data confirm the clinical potential interest of ADRB3 agonists in the pharmacological management of preterm labour.
\end{abstract}




\section{Background and aims}

The incidence of premature birth has risen over the past 15 years, mainly because of medically induced births, yet spontaneous preterm delivery rate continues its steady rise and remains relatively high in developed countries, despite preventative measures [1-3]. Approximately 6 to $12 \%$ of all pregnancies end up prematurely in Western countries, and the delivery of infants at preterm periods of gestation, and the clinical implications thereof, constitutes a major challenge for neonatologists [4]. The morbidity and mortality associated with preterm delivery outweigh all other clinical problems in obstetric practice [5-7]. Indeed preterm birth is the most frequent cause of infant death in the United States, accounting for at least one third of infant deaths [8]. Several stimulatory and inhibitory pathways regulate the balance of uterine quiescence and contractile activity during pregnancy, but the specific changes that govern the switch between these opposing functional states are still poorly understood.

These data explain that a logical research pursuit has been that of development of pharmacological agents that inhibit uterine contractions and ideally terminate the labor process, or delay delivery until gestation is further advanced.

Unfortunately the efficacy of current pharmacological treatments for the management of preterm labor is regularly questioned. Among these treatments, $\beta_{2}$-adrenoceptor (ADRB2) agonists are becoming less used worldwide as tocolytic agents because of important maternal and fetal side effects. For these reasons, and the lack of efficacy, much research in the last decade has focused on the development of novel agents, such as calcium channel blockers and oxytocin antagonists [9-12]. In countries outside of the United States, these agents have now largely displaced the use of ADRB2 agonists as tocolytic compounds, but the data to support their use, in terms of clinical efficacy, are lacking.

Although ADRB were originally sub-classified into ADRB1 and ADRB2 [13], another subtype, the ADRB3-subtype, has been since reported [14]. The ADRB3 shares 40 to $50 \%$ amino acid sequence identity with ADRB1 and ADRB2. It has been shown to mediate lipolysis in white adipose tissue and thermogenesis in brown adipose tissue $[15,16]$, and to inhibit the contractile activity of ileum and colon [17].

In the heart, $\mathrm{ADRB}$ pathways are the primary means of increasing cardiac performance in response to acute or chronic stress. The presence and function of the ADRB3 in the cardiovascular system is a conflicting debate. Indeed it has recently been suggested that ADRB3 are expressed in the endothelium of human coronary resistance arteries, or internal mammary arteries, and mediate adrenergic vasodilatation $[18,19]$.

Myometrium has always been described as expressing predominantly? ADRB2 [20-23] and the presence of ADRB3 had never been studied prior to our investigations presented here.

These works aimed to assess the presence and function of ADRB3 in human myometrium and to assess the influence of pregnancy in its expression as well as its ability to resist to agonist-induced desensitization.

\section{Results \\ The ADRB3 is present and functional in human near term myometrium}

Our first approach consisted of investigating the presence of the ADRB3 in human near-term myometrium [24]. Invitro functional studies were performed to compare the effects of ADRB2 and ADRB3 agonists on spontaneous contractions. SR 59119A, a selective ADRB3 agonist, produced a concentration-dependent inhibition of spontaneous contractions (Figure 1), with a maximal effect of $52 \pm$ $7 \%$ compared with $27 \pm 6 \%$ for salbutamol (Figure 2). The pharmacological evidence of the ADRB3-mediated nature of this effect was supported by the use of ADRB antagonists. Indeed, propranolol, at a concentration that blocks ADRB1\&2 but not ADRB3 [25], and ICI 118551, an ADRB2 antagonist, did not affect the SR 59119Ainduced relaxation whereas the ADRB3 antagonist [26], SR 59230A, significantly reduced the maximal effect of SR 59119A. To assess the nature of the second messenger involved in the uterorelaxant effect of SR 59119A, we measured the production of cAMP and cGMP after a stimulation of myometrial strips with SR 59119A or salbutamol. Both SR 59119A and salbutamol induced a significant increase in cAMP levels, but not of cGMP. The production of cAMP was antagonized by SR 59230A but not by propranolol for SR 59119A, providing confirmation of the ADRB3-mediated nature of this stimulation. Using an RT-PCR approach we found that mRNA expression was detected, as an expected $650 \mathrm{bp}$ fragment, in human myometrium (Figure 3). Hybridization to human $A D R B 3$ cDNA confirmed the identity of the amplified products.

A somewhat similar pharmacological study was published by Dennedy et al. in 2001 [27], on this occasion comparing the functional effects of the ADRB3 agonist BRL 37344, with those of the commonly used ADRB2 agonist, ritodrine, on human pregnant myometrial spontaneous or oxytocin-induced contractility. Mean maximal inhibition of contractility values of approximately $60 \%$ were reported for both compounds, at tissue bath concentrations in the 10-5 molar range. There was no difference 
$20 \mathrm{~min}$.
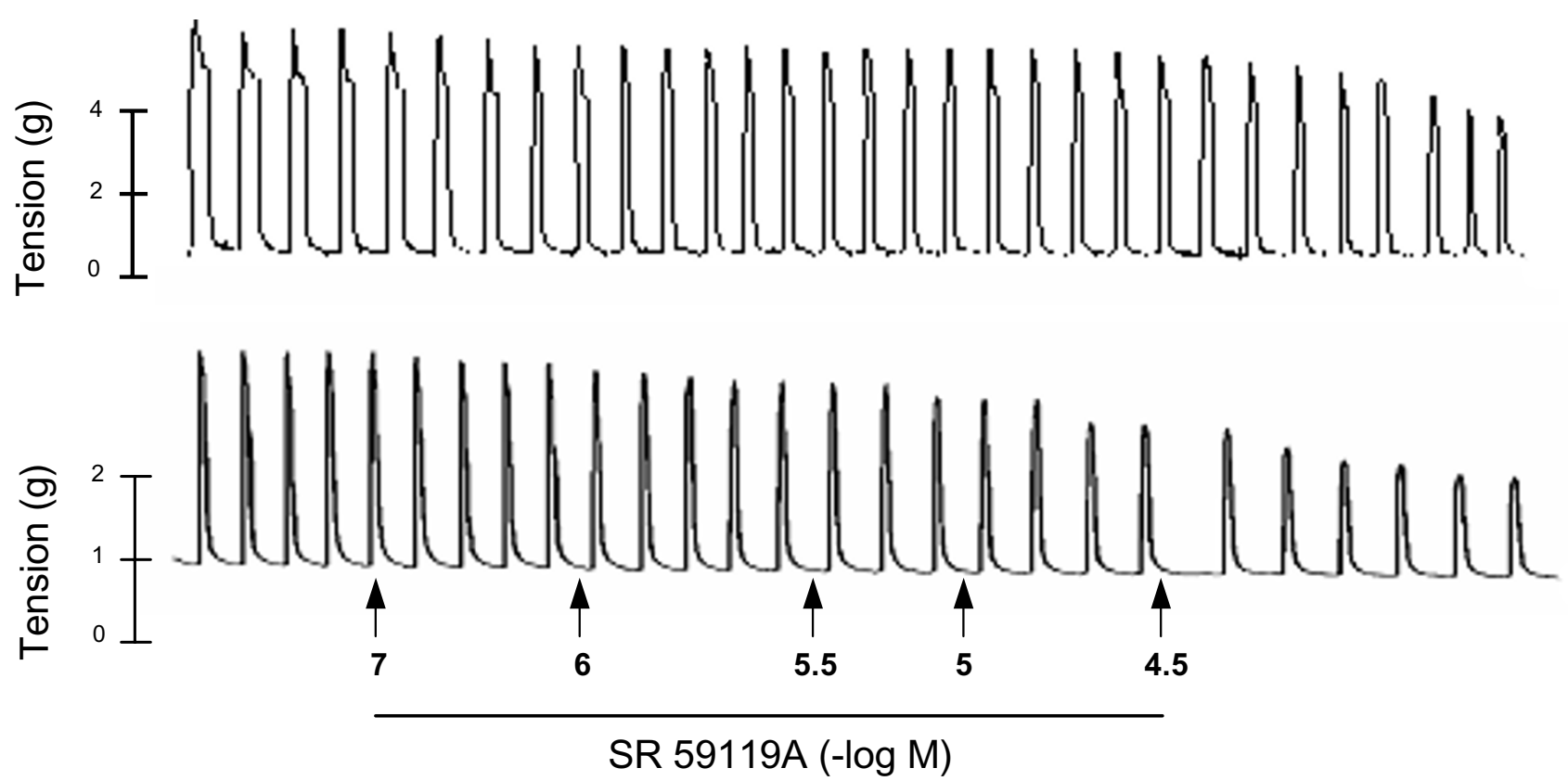

Figure I

Representative recording of the effect of SR 59II9A on spontaneous contractions of human non-pregnant (upper trace) and near-term (lower trace) myometrial strips.

between calculated pD2 values, or mean maximal inhibition achieved, for both compounds (Table 1).

As a logical follow on to the above findings, Dennedy et al. [28] further evaluated the selectivity of ADRB3 agonists in human myometrium. Using bupranolol (an ADRB1, ADRB2, and ADRB3 antagonist), propranolol (an ADRB1 and ADRB2 antagonist) and butoxamine (an ADRB2 antagonist), it was demonstrated that the myorelaxant effect of BRL 37344 was mediated via the ADRB3, although ritodrine may exert its effects via ADRB1, ADRB2 and ADRB3.

\section{The ADRB3 is predominant over the ADRB2 and its expression is increased during pregnancy}

Whereas the existence of the third ADRB subtype had not been shown yet formally, we previously described that ADRB2 were predominant (65\%) over ADRB1 in the human myometrium and that the number of ADRB was diminished at the end of pregnancy [20]. In the light of our new results, we wanted to assess the influence of preg- nancy on the function and the expression of the myometrial ADRB3-subtype [29]. To this end, we performed invitro studies in human non-pregnant and near-term myometrium and found that SR 59119A inhibited spontaneous contractions of pregnant myometrial strips in a greater extent than that of non-pregnant myometrial strips $\left(\mathrm{E}_{\max }=61 \pm 5 \% v s .44 \pm 5 \%\right.$ for pregnant and non-pregnant myometrium respectively). On the contrary, salbutamol was less efficient in pregnant than in non-pregnant myometrial strips $\left(\mathrm{E}_{\max }=29 \pm 4 \%\right.$ vs. $54 \pm 8 \%$ ). Binding competition studies, transcripts and protein analysis were then performed to determine whether any changes in the number of ADRB2 and ADRB3 binding sites and in the transcript and protein expression might explain the observed change in the contractile response between nonpregnant and pregnant myometrium to ADRB2 and ADRB3 agonists. Although two populations of binding sites corresponding to ADRB2 and ADRB3 were identified in both non-pregnant and pregnant myometrium, we found a clear predominance of the ADRB3 subtype, a result that contrasts with conventional belief. Moreover, 


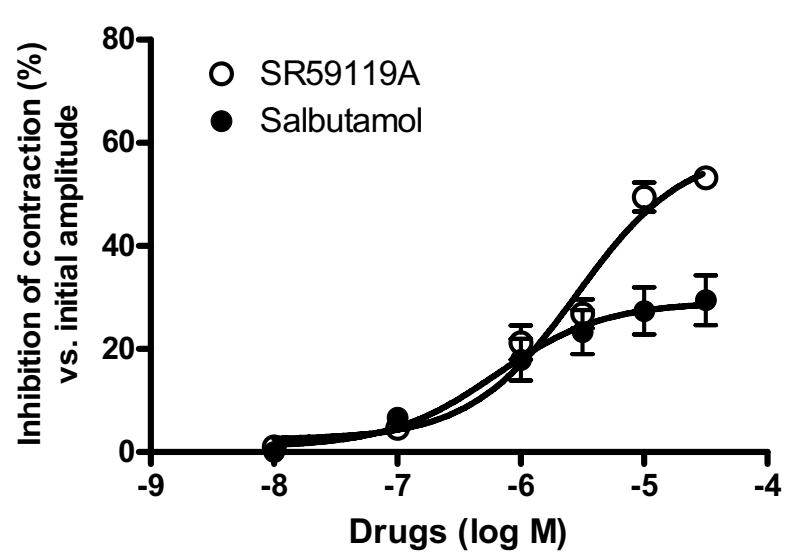

Figure 2

Concentration-response curve for SR591 19 and Salbutamol (ADRB3 and ADRB2 agonists respectively) in human near term myometrium.

ADRB3 binding sites were 2-fold more numerous at the end of pregnancy, whereas, according to the work of Gsell et al. [30], we found no modification in the number of ADRB2 binding sites in non-pregnant compared to pregnant human myometrium.

Densitometric analysis of the RT-PCR experiments indicated a slight decrease in the signal for ADRB2 mRNA ($27.4 \%$ ) in near-term myometrium comparatively to nonpregnant tissue whereas the signal for ADRB3 mRNA was increased in pregnant myometrium (+66.3\%).

In agreement with Chanrachakul et al. [31], densitometric immunoblot analysis indicated no change in the intensity of the signal for the ADRB2 in the myometrium of nearterm compared to non-pregnant women. At the opposite, an increase $(+40 \%)$ in the intensity of the signal for the $A D R B 3$ protein was observed in pregnant compared with non-pregnant myometrium (Figure 4).
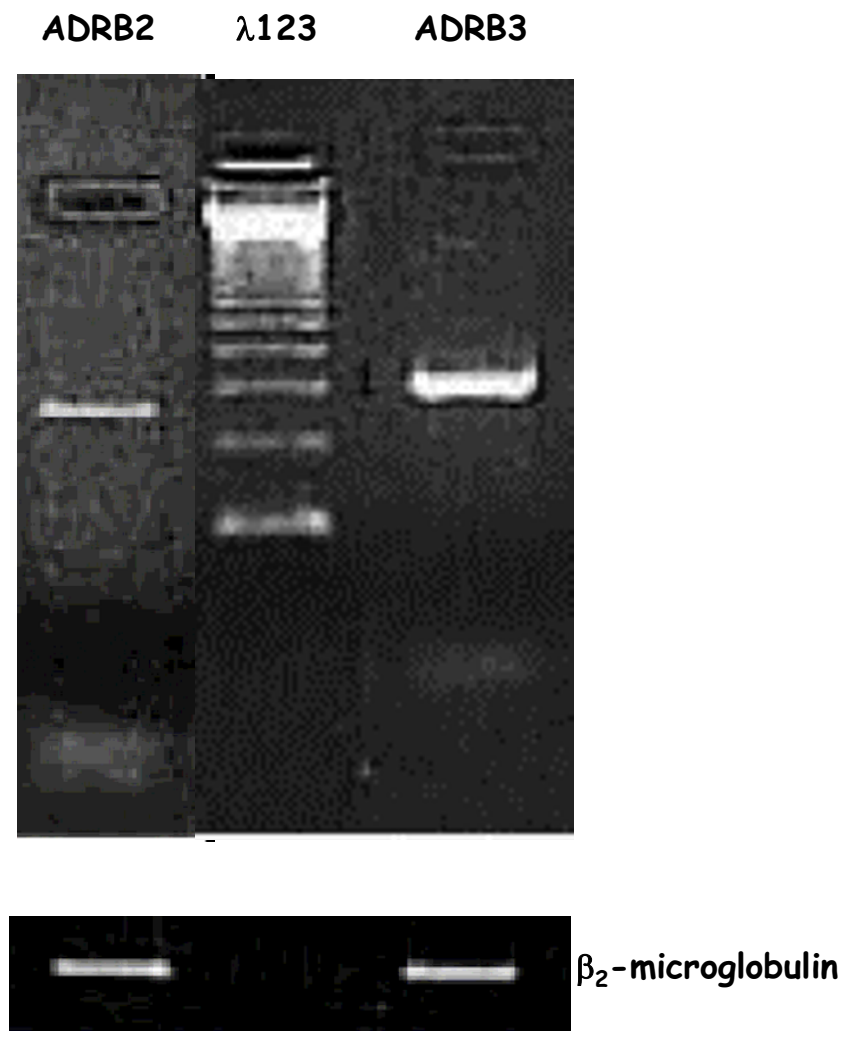

Figure 3

Representative RT-PCR analysis of the mRNA steady-state levels for ADRB2 and ADRB3 in human pregnant myometrium. The I23-bp DNA ladder $\left(\begin{array}{ll}\lambda & 123\end{array}\right)$ was used to estimate the size of the PCR products, and beta 2 microglobulin expression was used as a standard reference.

\section{Contrary to the ADRB2, the ADRB3 is resistant to agonist- induced desensitization}

Besides their maternal and fetal side effects, ADRB2 agonists display a lack of efficacy in late pregnancy or after a chronic exposure $[32,33]$. This loss of efficacy, also called desensitization, may be partly explained by a decreased number of ADRB2 at the end of pregnancy, as well as by an impairment of the coupling between the receptor and its effector, the adenylyl cyclase. ADRB3 was suggested to be less prone than ADRB2 to desensitisation [34]. This

Table I: Emax, pD2 and intrinsic activity (IA) for the different ADRB2 or ADRB3 agonists presented in this paper

\begin{tabular}{lccc}
\hline Compounds & Emax & pD2 & IA \\
\hline Isoprenaline & $58 \% \pm 9 \%$ & $7.32 \pm 0.62$ & $100 \%($ ref $)$ \\
Salbutamol & $27 \% \pm 6 \%$ & $6.0 \pm 0.48$ & $48 \% \pm 7 \%$ \\
Ritodrine & $62 \% \pm 5 \%$ & $7.26 \pm 0.48$ & $107 \% \pm 6 \%$ \\
BRL 37344 & $60 \% \pm 4 \%$ & $7.64 \pm 0.53$ & $103 \% \pm 4 \%$ \\
SR59I19 & $52 \% \pm 7 \%$ & $5.65 \pm 0.14$ & $90 \% \pm 7 \%$
\end{tabular}

Emax is expressed as a percentage of inhibition compared with initial amplitude of the contractions. The intrinsic activity (\%IA) relative to the maximal effect of (-)-isoproterenol indicate the inhibition of the initial amplitude of spontaneous contractions. 
A

ADRB2

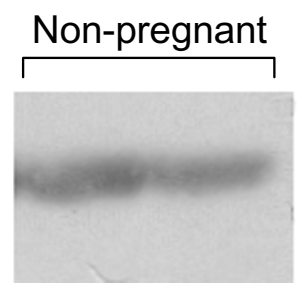

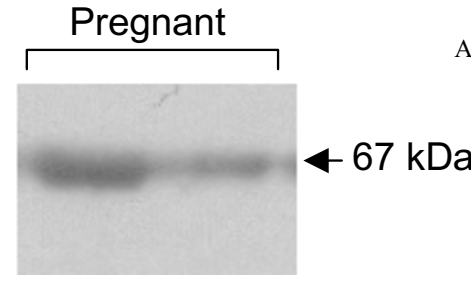

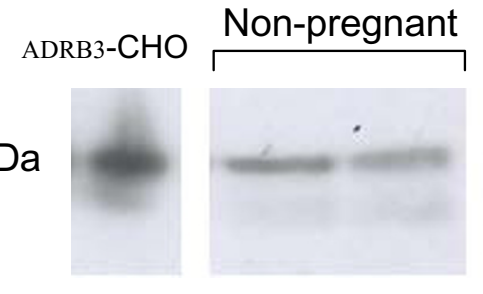

$68 \mathrm{kDa}$

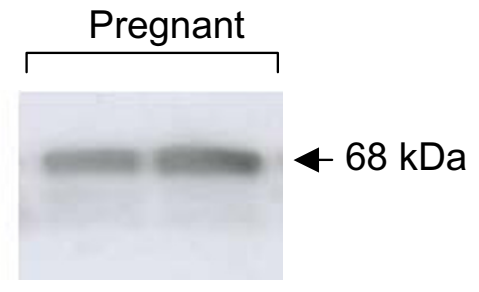

B

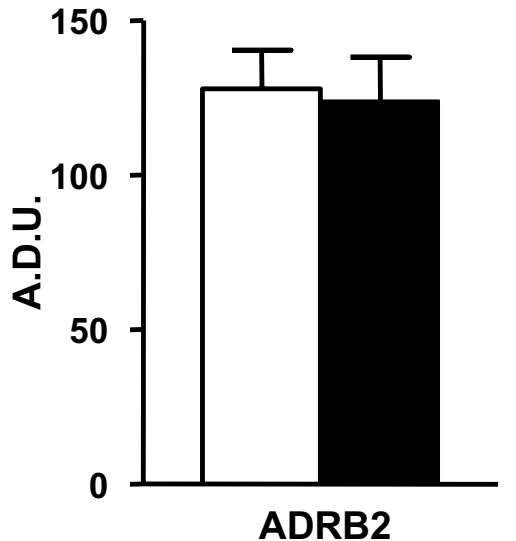

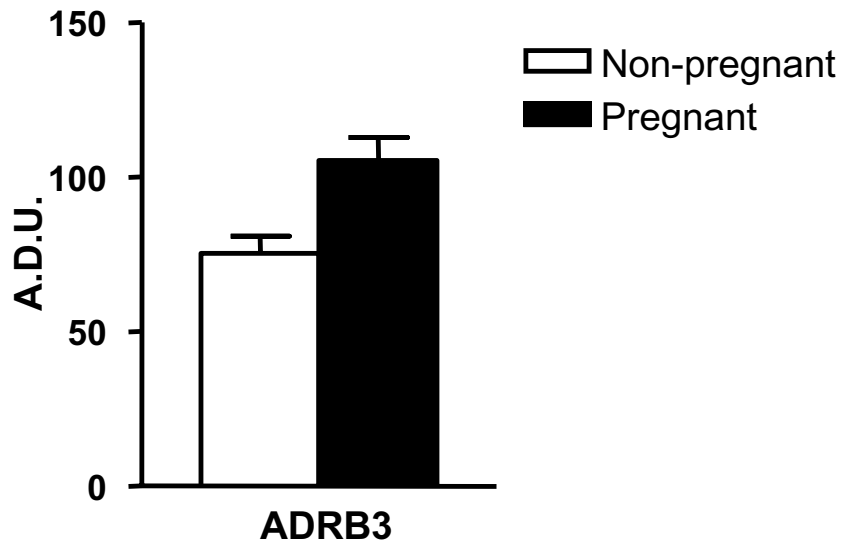

\section{Figure 4}

ADRB2 and ADRB3 immunoreactive proteins expression in myometrium of non-pregnant and pregnant women. (A) Representative western blot analysis of ADRB2- and ADRB3 expression in plasma membranes from myometrium of non-pregnant and pregnant women. Expected sizes are $67 \mathrm{kDa}$ for ADRB2 and $68 \mathrm{kDa}$ for ADRB3. These experiments were performed on myometrium from five non-pregnant and five pregnant women. Homogenate of Chinese Hamster Ovary cells transfected with the human ADRB3 (ADRB3-CHO) was used as positive control. (B) Analysis of the expression of ADRB2 and ADRB3 immunoreactive proteins in myometrium of non-pregnant and pregnant women. A.D.U. represents the intensity of the bands evaluated by densitometry. Each bar represents the mean \pm s.e.m. from five different non-pregnant and five different pregnant women. Figure reproduced from the paper by Rouget et al. [29].

particularity may be due to a lack of recognition sites in ADRB3 for the cyclic AMP-dependent protein kinase and for the G-protein coupled receptor kinase implicated in the desensitization process of ADRB2. In order to confirm this hypothesis in human near-term myometrium, we investigated the effects of a long-term $(15 \mathrm{~h})$ exposure of myometrial strips to SR 59119A or to salbutamol on the inhibition of spontaneous contractile activity and on the cAMP production induced by these agonists [35]. In our experimental conditions, we demonstrated that ADRB2 undergoes functional desensitization after long-term exposure to salbutamol, since salbutamol concentrationresponse curve (CRC) was shifted by a $15 \mathrm{~h}$ salbutamol pre-incubation with a significant difference in $-\operatorname{logEC_{20}}$ 
values $(6.31 \pm 0.13$ vs. $5.58 \pm 0.24$, for control and $15 \mathrm{~h}$ salbutamol pre-treatment respectively, $\mathrm{P}<0.05)$. Additionally a $15 \mathrm{~h}$ exposure of myometrial strips to salbutamol significantly reduced the salbutamol-induced $(0.60 \pm$ 0.26 vs. $1.54 \pm 0.24$ pmol. $\mathrm{mg}^{-1}$ protein, $\left.\mathrm{P}<0.05\right)$ cAMP production. In contrast, a sustained stimulation by SR 59119A did not modify its subsequent functional effects.

A 15 h salbutamol exposure of myometrial strips significantly reduced the ADRB2 but not the ADRB3 binding sites density whereas no decrease in the number of ADRB2 and ADRB3 binding sites was observed after a $15 \mathrm{~h}$ SR 59119A treatment. RT-PCR experiments and PDE4 activity measurement were performed in order to assess some of the mechanisms that could be involved in desensitization process and we found that neither $A D R B 2$ and $A D R B 3$ mRNA expression levels nor PDE4 activity were affected by salbutamol or SR 59119A treatments.

\section{Discussion and conclusion}

Taken altogether our results indicate that ADRB3 is: i) present and functional in human near term myometrium, ii) predominant over ADRB2 in human myometrium and over-expressed in pregnancy, and iii) resistant to the longterm agonist-induced desensitization in human myometrium at the end of pregnancy.

The presence of ADRB3 in human myometrium was confirmed in a work by Hakak et al. [36] who compared the ADRB3 expression in Human and mouse. In this paper the two key messages were as follows: (i) ADRB3 expression differs strongly between Human and Mouse myometrium and (ii) human ADRB3 is highly expressed in placenta, ovaries and myometrium (the relative level of expression being as follow: placenta $=$ bladder $>$ aorta $>$ ovary $>$ myometrium)

To conclude, our work strongly suggests the ADRB3 as a potential target for tocolytic agents. The greater relaxant effectiveness of ADRB3 agonists compared to ADRB2 mimetics, as well as the resistance of ADRB3 to sustained agonist-induced desensitization strengthens this concept. We previously mentioned maternal and fetal cardiovascular side effects as one of the major limitations for ADRB2 agonists' use in clinical practice. There is strong evidence to suggest a favorable safety profile, probably better than that of ADRB2 agonists and calcium channels antagonists. Indeed clinical trials, that were designed to assess the effect of ADRB3 agonists on human metabolism, did not reveal any significant change in heart rate, blood pressure, plasma glucose, insulin or potassium levels [37]. Although the therapeutic efficiency of the ADRB3 agonists remains to be established, we believe that ADRB3 agonists may have considerable future pharmaceutical implications in the clinical management of preterm labor.

\section{List of abbreviations}

ADRB, beta-adrenergic receptor; CAMP, cyclic adenosine monophosphate; CGMP, cyclic guanosine monophosphate; CRC, concentration response curve; Emax, maximal efficacy; PDE, phosphodiesterases; RT-PCR, real time polymerase chain reaction.

\section{Competing interests}

The authors declare that they have no competing interests.

\section{Acknowledgements}

The authors whish to express their gratitude to the Obstetric \& Gynaecology Departments of: (I) Galway Hospital (Ireland, Pr Morrison); Antoine Béclère Hospital, Clamart, (France, Pr. Frydmann); Hôpital du Bocage, Dijon, (France, Pr. Sagot); Hôpital Port-Royal Paris, (France, Pr. Cabrol), La Fe Hospital Valencia (Spain, Pr. Perales), for making tissue samples available to us. They also want to thank Pr. Advenier and coworkers (Paris, France) and Pr. Morcillo and coworkers (Valencia, Spain) for scientific and technical support for designing and conducting experimentations. Special thanks go to $\mathrm{Dr}$ Catherine Loustalot for first suggesting assessing the presence of $A D R B 3$ in human near-term myometrium.

Authors of this paper acknowledge the financial support of Ferring, Serono and Perkin Elmer for covering publication charges as well as that of the EU project SAFE (The Special Non-Invasive Advances in Fetal and Neonatal Evaluation Network) for financial support of the workshop.

This article has been published as part of BMC Pregnancy and Childbirth Volume 7, Supplement I, 2007: Proceedings of the First and Second European Workshops on Preterm Labour of the Special Non-Invasive Advances in Fetal and Neonatal Evaluation (SAFE) Network of Excellence. The full contents of the supplement are available online at http://www.biomedcen tral.com/l47I-2393/7? issue=SI.

\section{References}

I. Goldenberg RL, Rouse DJ: Prevention of premature birth. $N$ Engl J Med I998, 339:3 I3-20.

2. Ananth CV, Misra DP, Demissie K, Smulian JC: Rates of preterm delivery among Black women and White women in the United States over two decades: an age-period-cohort analysis. Am J Epidemiol 200I, 154:657-65.

3. Martin JA, Hamilton BE, Sutton PD, Ventura SJ, Menacker F, Kirmeyer S: Births: final data for 2004. Natl Vital Stat Rep 2006, 55: I-I0I.

4. lannucci TA, Tomich PG, Gianopoulos JG: Etiology and outcome of extremely low-birth-weight infants. Am J Obstet Gynecol I996, 174:1896-900. discussion 1900-2.

5. Creasy RK: Preterm birth prevention: where are we? Am J Obstet Gynecol 1993, 168:1223-30.

6. Morrison J], Rennie JM: Clinical, scientific and ethical aspects of fetal and neonatal care at extremely preterm periods of gestation. Br J Obstet Gynaecol 1997, 104:1341-50.

7. Demissie K, Rhoads GG, Ananth CV, et al: Trends in preterm birth and neonatal mortality among blacks and whites in the United States from 1989 to 1997. Am J Epidemiol 200I, I 54:307-I5.

8. Callaghan WM, MacDorman MF, Rasmussen SA, Qin C, Lackritz EM: The contribution of preterm birth to infant mortality rates in the United States. Pediatrics 2006, I I 8:1566-73.

9. Slattery MM, Morrison JJ: Preterm delivery. Lancet 2002, 360: 1489-97.

10. Gyetvai K, Hannah ME, Hodnett ED, Ohlsson A: Tocolytics for preterm labor: a systematic review. Obstet Gynecol 1999, 94:869-77.

II. Romero R, Sibai BM, Sanchez-Ramos L, et al.: An oxytocin receptor antagonist (atosiban) in the treatment of preterm labor: a randomized, double-blind, placebo-controlled trial with tocolytic rescue. Am J Obstet Gynecol 2000, I 82: | I73-83. 
12. Tsatsaris V, Papatsonis D, Goffinet F, Dekker G, Carbonne B: Tocolysis with nifedipine or beta-adrenergic agonists: a metaanalysis. Obstet Gynecol 200I, 97:840-7.

13. Lands AM, Arnold A, McAuliff JP, Luduena FP, Brown TG Jr: Differentiation of receptor systems activated by sympathomimetic amines. Nature 1967, 214:597-8.

14. Emorine LJ, Marullo S, Briend-Sutren MM, et al:: Molecular characterization of the human beta 3-adrenergic receptor. Science 1989, 245: I|| 8-2I.

15. Arch JR, Ainsworth AT, Cawthorne MA, et al.: Atypical betaadrenoceptor on brown adipocytes as target for anti-obesity drugs. Nature 1984, 309:163-5.

16. Lonnqvist F, Krief S, Strosberg AD, Nyberg S, Emorine LJ, Arner P: Evidence for a functional beta 3-adrenoceptor in man. $\mathrm{Br}$ j Pharmacol 1993, I I 0:929-36.

17. Bardou M, Dousset B, Deneux-Tharaux $C$, et al:: In vitro inhibition of human colonic motility with SR 59II9A and SR 59104A evidence of a beta3-adrenoceptor-mediated effect. Eur J Pharmacol 1998, 353:281-7.

18. Dessy C, Moniotte S, Ghisdal P, Havaux X, Noirhomme P, Balligand $\mathrm{JL}$ : Endothelial beta3-adrenoceptors mediate vasorelaxation of human coronary microarteries through nitric oxide and endothelium-dependent hyperpolarization. Circulation 2004 I I 0:948-54.

19. Rozec B, Serpillon S, Toumaniantz G, et al:: Characterization of beta3-adrenoceptors in human internal mammary artery and putative involvement in coronary artery bypass management. J Am Coll Cardiol 2005, 46:35I-9.

20. Breuiller M, Rouot B, Leroy MJ, Blot P, Kaplan L, Ferre F: Adrenergic receptors in inner and outer layers of human myometrium near term: characterization of beta-adrenergic receptor sites by [I25I]-iodocyanopindolol binding. Gynecol Obstet Invest 1987, 24:28-37.

21. Story ME, Hall S, Ziccone SP, Paull JD: Effects of adrenaline, isoprenaline and forskolin on pregnant human myometrial preparations. Clin Exp Pharmacol Physiol 1988, 15:703-13.

22. Doggrell SA: Comparison of the attenuating effects of four beta-adrenoceptor agonists on rat isolated uterus and aorta. Clin Exp Pharmacol Physiol 1995, 22:670-4.

23. Engstrom T, Bratholm P, Vilhardt H, Christensen NJ: Effect of oxytocin receptor and beta2-adrenoceptor blockade on myometrial oxytocin receptors in parturient rats. Biol Reprod 1999, 60:322-9.

24. Bardou M, Loustalot C, Cortijo J, et al.: Functional, biochemical and molecular biological evidence for a possible beta(3)adrenoceptor in human near-term myometrium. Br J Pharmacol 2000, 130: 1960-6.

25. Roberts SJ, Russell FD, Molenaar P, Summers RJ: Characterization and localization of atypical beta-adrenoceptors in rat ileum. $\mathrm{Br}$ J Pharmacol 1995, I 1 6:2549-56.

26. Nisoli E, Tonello C, Landi M, Carruba MO: Functional studies of the first selective beta 3-adrenergic receptor antagonist SR 59230A in rat brown adipocytes. Mol Pharmacol 1996, 49:7-14.

27. Dennedy MC, Friel AM, Gardeil F, Morrison J]: Beta-3 versus beta2 adrenergic agonists and preterm labour: in vitro uterine relaxation effects. Bjog 200I, 108:605-9.

28. Dennedy MC, Houlihan DD, McMillan H, Morrison JJ: Beta2- and beta3-adrenoreceptor agonists: human myometrial selectivity and effects on umbilical artery tone. Am J Obstet Gynecol 2002, 187:64I-7.

29. Rouget C, Bardou M, Breuiller-Fouche M, et al.: Beta3-adrenoceptor is the predominant beta-adrenoceptor subtype in human myometrium and its expression is up-regulated in pregnancy. J Clin Endocrinol Metab 2005, 90:1644-50.

30. Gsell S, Eschenhagen T, Kaspareit G, et al:: Apparent up-regulation of stimulatory G-protein alpha subunits in the pregnant human myometrium is mimicked by elevated smoothelin expression. Faseb J 2000, 14:17-26.

31. Chanrachakul B, Matharoo-Ball B, Turner A, et al.: Reduced expression of immunoreactive beta2-adrenergic receptor protein in human myometrium with labor. J Clin Endocrinol Metab 2003, 88:4997-500I.

32. Berg G, Andersson RG, Ryden G: Beta-adrenergic receptors in human myometrium during pregnancy: changes in the number of receptors after beta-mimetic treatment. $\mathrm{Am}$ Obstet Gynecol 1985, I 5 I:392-6.
33. Litime MH, Pointis G, Breuiller M, Cabrol D, Ferre F: Disappearance of beta-adrenergic response of human myometrial adenylate cyclase at the end of pregnancy. J Clin Endocrinol Metab 1989, 69:1-6.

34. Nantel F, Bouvier M, Strosberg AD, Marullo S: Functional effects of long-term activation on human beta 2 - and beta 3-adrenoceptor signalling. Br J Pharmacol | 995, I | 4: | 045-5 |.

35. Rouget C, Breuiller-Fouche M, Mercier FJ, et al:: The human nearterm myometrial beta3-adrenoceptor but not the beta2adrenoceptor is resistant to desensitisation after sustained agonist stimulation. Br J Pharmacol 2004, I 41:83I-4I.

36. Hakak Y, Shrestha D, Goegel MC, Behan DP, Chalmers DT: Global analysis of G-protein-coupled receptor signaling in human tissues. FEBS Lett 2003, 550: II-7.

37. van Baak MA, Hul GB, Toubro S, et al.: Acute effect of L-796568, a novel beta 3-adrenergic receptor agonist, on energy expenditure in obese men. Clin Pharmacol Ther 2002, $71: 272-9$.

Publish with BioMed Central and every scientist can read your work free of charge

"BioMed Central will be the most significant development for disseminating the results of biomedical research in our lifetime. "

Sir Paul Nurse, Cancer Research UK

Your research papers will be:

- available free of charge to the entire biomedical community

- peer reviewed and published immediately upon acceptance

- cited in PubMed and archived on PubMed Central

- yours - you keep the copyright

BioMedcentral 